\title{
The Analysis of Bilateral Bidding Model of Electricity Market Based on Bayesian Nash Equilibrium
}

\author{
Yan-hong Li \\ North China Electric Power University, Baoding, 071003, China \\ redlyh@126.com
}

\begin{abstract}
Keywords: Bayesian Nash Equilibrium; Electricity Market; Bilateral Bidding Model
\end{abstract}
\begin{abstract}
This paper, based on the incomplete information game theory, analyzes the direct bilateral bidding transactions between electric power generator and electric power consumer. Then, we analyze the existence of the Bayesian Nash equilibrium solutions. The analysis result manifests that it is of obvious benefits for the electric power producer to use game theory to guide their bidding strategies. And this article can also provide some policy guidance for China's electricity market reforms.
\end{abstract}

\section{Introduction}

In the recent years, with the coal prices rising sharply, the electricity generation enterprises' profit decreased so much. Generating more electric power cannot lead to more gains; what's worse, it may lead to even losses. Therefore, the electric power shortage is not due to inadequate power generation capacity. Because the contradictions between electric power price determination mechanism and coal price determination mechanism for that the coal price level is determined by the market supply and demand levels, compared with that, the electric power price level is determined by the government considering the importance of electric power to the national constructions. The high electric coal demand, largely results in the existence of large amount of high energy-consuming small coal-fired power plants. At present, the national unit capacity of power stations of which the single-machine capacity is less than 13.5 million kilowatts still remains about 140 million kilowatts. The average coal consumption generating one kilowatt-hour of these units is larger than one hundred and fifty grams compared with the larger units. National coal production capacity would quickly achieve balance between supply and demand if the small power generation capacity units were alternated by large ones. It is crucial reason for the current coal-fired contradiction that China's electric power trading and scheduling is not reasonable.

It is imperative to improve the electricity power transaction and scheduling mode, put the power buyer and power seller having trade directly into practice to decrease the intermediate transaction costs. Game theory is the powerful analysis tool when dealing with the direct transactions between the power producer and power buyer. Taking the actual market into account, the electric power producer and the electric power buyer haven't grasped each other's information completely; we will analyze the direct transactions between power seller and power buyer based on the incomplete information game theory.

\section{The Methodology of Incomplete Information Game Theory}

The general description of $\mathrm{N}$-person incomplete information game theory can be expressed as $G=\left\{\mathrm{A}_{1}, \cdots \mathrm{A}_{\mathrm{n}} ; \theta_{1}, \cdots \theta_{\mathrm{n}} ; \mathrm{p}_{1}, \cdots \mathrm{p}_{1} ; \mathrm{u}_{1}, \cdots \mathrm{u}_{n}\right\} ; \mathrm{n}$ represents the number of independent game players; ${ }_{i}$ represents the possible bidding space of game player $\mathrm{i} ;{ }^{\Theta_{i}}$ represents the type-contingent space of game player $\mathrm{i}$; the conditional probability $p_{i}=p_{i}\left(\theta_{-i} \mid \theta_{i}\right)$ represents the probability of every possible type combination of other game players when the type of game player i is $\theta_{i} ; u_{i}$ represents 
utility of game player i. The player i knows exactly his own type $\theta_{i} \in \Theta_{i}$, but the game player i don't know the other players' type.

With the assumption that the game player i just know his own type but not the others' type, the game player i would choose his type-contingent strategy $a_{i}\left(\theta_{i}\right)$ to maximize his own expected utility. The expected utility of game player $\mathrm{i}$ is defined as below:

$$
v_{i}=\sum_{\theta_{-i}} p_{i}\left(\theta_{-i} \mid \theta_{i}\right) u_{i}\left(a_{i}\left(\theta_{i}\right), a_{-i}\left(\theta_{-i}\right) ; \theta_{i}, \theta_{-i}\right)
$$

Had the above definitions, the definition of Bayesian Nash equilibrium can be expressed as below: The pure strategy Bayesian Nash equilibrium of N-person incomplete information static game theory is a type-contingent strategy combination $\left\{a_{i}^{*}\left(\theta_{i}\right)\right\}_{i=1}^{n}$, player i choose his strategy to maximize his utility with the assumption that the player i knows his own type ${ }^{\theta_{i}}$ and the others' type-contingent strategy $a_{-i}^{*}\left(\theta_{-i}\right)$.In other words, the strategy combination $a^{*}=\left(a^{*}\left(\theta_{1}\right), \cdots a^{*}\left(\theta_{\mathrm{n}}\right)\right)$ would be the Bayesian Nash equilibrium if the formula

$$
a_{i}^{*}\left(\theta_{i}\right) \in \underset{a_{i}}{\arg \max } \sum p_{i}\left(\theta_{-i} \mid \theta_{i}\right) u_{i}\left(a_{i}, \mathrm{a}_{-i}^{*}\left(\theta_{-i}\right) ; \theta_{i}, \theta_{-i}\right)
$$

is satisfied for every game player $\mathrm{i}$.

\section{Model Simplification and Bidding Decision-Making Analysis of Electricity Market}

Game Model in Electricity Market. There are three ways for making electric power price; individual cost pricing method, standard cost pricing, market-pricing method. Individual cost pricing method is essentially a "cost plus" model. This kind of electric power price is consists of all the costs, expenses, tariff and a certain amount of Return of Investment. The standard cost pricing method is essentially the "same electric net, the same quality, the same price" mode. This kind of power pricing method sets the power price according to different electric power quality. Market pricing method is this kind of method in which the price is determined by competition. However, in this article, the electric power price is determined by both bidding price of the power buyer and the asking price of the power seller.

Here are some assumptions for our modeling:

(1)The cost of the electric power seller is random variable $\mathrm{c}$; the value of the electricity to the buyer is random variable $\mathrm{v}$. $\mathrm{c}$ and $\mathrm{v}$ subject to the uniform distribution, and the lower limit is 0 , the upper limit is $1 . c \in[0,1], v \in[0,1]$. The distribution function $P($.$) is the common knowledge.$

(2) The electric power seller asking price for the electric power while electricity buyer bid price for the electric power at the same time. $P_{s}$, ranging from 0 to 1 , is the bidding price of electricity power seller. Accordingly, ${ }_{b}$, ranging from 0 to 1 , is the bidding price of the electricity power buyer;

The utility function of the buyer and seller can be expressed as below;

$$
\begin{aligned}
& u_{s}=\left\{\begin{array}{ccc}
\left(p_{s}+p_{b}\right) / 2-c & \text { if } & p_{s} \leq p_{b} \\
0 & \text { if } & p_{s} \geq p_{b}
\end{array}\right. \\
& u_{b}=\left\{\begin{array}{cll}
v-\left(p_{s}+p_{b}\right) / 2 & \text { if } & p_{s} \leq p_{b} \\
0 & \text { if } & p_{s} \geq p_{b}
\end{array}\right.
\end{aligned}
$$

That means the seller and the buyer will have their transaction if $p_{s} \leq p_{b}$. 
The Algorithm Convergence and the Existence of the Nash Equilibrium. In the case of incomplete information, only power seller knows that $\mathrm{c}$, the power buyer knows that $\mathrm{v}$ for that $\mathrm{c}$ is the seller's type and $\mathrm{v}$ is the buyer's type. In this Bayesian Nash equilibrium, ${ }^{s}$, the strategy of power seller, is the function of the random variable $\mathrm{c}$; $p_{b}$, the strategy of power buyer, is the function of the random variable $\mathrm{v}$. The strategy combination $\left(p_{s}^{*}(c), p_{b}^{*}(v)\right)$ is Bayesian Nash equilibrium if the following two conditions are satisfied.

(1) Maximization of the electricity power seller's utility: $p_{s}^{*}(c)$ is the optimal solution of the following questions for any value of the random variable $\mathrm{c}$.

$$
\max _{p_{s}}\left[\frac{1}{2}\left(p_{s}+E\left[p_{b}(v) \mid p_{b}(v) \geq p_{s}\right]\right)-c\right] \operatorname{Pr} o b\left\{p_{b}(v) \geq p_{s}\right\}
$$

Here, $E\left[p_{b}(v) \mid p_{b}(v) \geq p_{s}\right]$ is seller's expectancy bidding price of the buyer under the conditions that the seller's asking price is lower than the buyer's bidding price.

(2) Maximization of the electricity power buyer's utility: $p_{b}^{*}(v)$ is the optimal solution of the following questions for any value of the random variable v.

$$
\max _{p_{b}}\left[v-\frac{1}{2}\left(p_{b}+E\left[p_{s}(c) \mid p_{b} \geq p_{s}(c)\right]\right)\right] \operatorname{Pr} o b\left\{p_{b} \geq p_{s}(c)\right\}
$$

Here, $\left.\left.E\left[p_{s}(c) \mid p_{b} \geq p_{s}(c)\right]\right)\right]$ is buyer's expectancy bidding price of the seller under the conditions that the seller's asking price is lower than the buyer's bidding price.

In order to facilitate the discussion of the model, we consider the following linear strategy equilibrium:

$$
p_{s}(c)=\alpha_{s}+\beta_{s}^{*} c, \quad p_{b}(v)=\alpha_{b}+\beta_{b} * v
$$

$p_{b}$ subjects to the uniform distribution on $\alpha_{b}-\beta_{b}$ for that the random variable v subjects to the uniform distribution on 0 -1.so the probability of the case that $p_{b}(v)$ is greater than $p_{s}$ can be expressed as follows:

$$
\begin{gathered}
\operatorname{Pr} o b\left\{p_{b}(v) \geq p_{s}\right\}=\operatorname{Pr} o b\left\{\alpha_{b}+\beta_{b} * v \geq p_{s}\right\}=\operatorname{Pr} o b\left\{v \geq \frac{p_{s}-\alpha_{b}}{\beta_{b}}\right\}=\frac{\alpha_{b}+\beta_{b}-p_{s}}{\beta_{b}} \\
E\left[p_{b}(v) \mid p_{b}(v) \geq p_{s}\right]=\frac{\frac{1}{\beta_{b}} \int_{p_{s}}^{\alpha_{b}+\beta_{b}} x d x}{\operatorname{Pr} o b\left\{p_{b}(v) \geq p_{s}\right\}}=\frac{1}{2}\left(p_{s}+\alpha_{b}+\beta_{b}\right)
\end{gathered}
$$

Put (1-3) and (1-4) these two equations into the seller's utility function, we can get the target function expressed as below:

$$
\max _{p_{s}}\left(\frac{1}{2}\left[p_{s}+\frac{1}{2}\left(p_{s}+\alpha_{b}+\beta_{b}\right)\right]-\mathrm{c}\right) \frac{\alpha_{b}+\beta_{b}-p_{s}}{\beta_{b}}
$$

Optimal first-order conditions means: 


$$
p_{s}=\frac{1}{3}\left(\alpha_{b}+\beta_{b}\right)+\frac{2}{3}
$$

The above conclusions manifest that the seller's optimal reaction function would also be linear if the seller choose the linear strategy.

Similarly, $p_{s}$ subjects to the uniform distribution on $\alpha_{s}-\beta_{s}$ for that the random variable c subjects to the uniform distribution on $0-1$.so the probability of the case that $p_{b}$ is greater than $p_{s}(\mathrm{c})$ can be expressed as follows:

$$
\begin{aligned}
& \operatorname{Pr} o b\left\{p_{b} \geq p_{s}(\mathrm{c})\right\}=\operatorname{Pr} o b\left\{p_{s} \geq \alpha_{s}+\beta_{b} * c\right\}=\operatorname{Pr} o b\left\{c \leq \frac{p_{b}-\alpha_{s}}{\beta_{s}}\right\}=\frac{p_{b}-\alpha_{s}}{\beta_{s}} \\
& E\left[p_{s}(c) \mid p_{b} \geq p_{s}(\mathrm{c})\right]=\frac{\frac{1}{\beta_{s}} \int_{\alpha_{s}}^{p_{b}} x d x}{\operatorname{Pr} o b\left\{p_{b} \geq p_{s}(\mathrm{c})\right\}}=\frac{1}{2}\left(\alpha_{s}+p_{b}\right)
\end{aligned}
$$

Put (1-5) and (1-6) these two equations into the buyer's utility function, we can get the target function expressed as below:

$$
\max _{p_{b}}\left(v-\frac{1}{2}\left[p_{b}+\frac{1}{2}\left(\alpha_{s}+p_{b}\right)\right]\right) \frac{p_{b}-\alpha_{s}}{\beta_{s}}
$$

Optimal first-order conditions means:

$$
p_{b}=\frac{1}{3} * \alpha_{s}+\frac{2}{3} * v
$$

Solving these two first-order conditions, we can get the linear strategy equilibrium function expressed as below:

$$
p_{s}(\mathrm{c})=\frac{1}{4}+\frac{2}{3} * \mathrm{c} \quad p_{b}(v)=\frac{1}{12}+\frac{2}{3} * v
$$

With the assumption that the seller and the buyer choose the linear strategy, if $\mathrm{c}$ is greater than $3 / 4$,the asking price of the seller is lower than the cost, but it is higher than the supreme bidding price of the buyer for the highest bidding price is $p_{b}(1)=1 / 12+2 / 3=3 / 4$.so, the transaction that the price is lower than the cost of electric production will not happen; similarly, the transaction that the bidding price of the buyer is higher than the value with the condition that $\mathrm{v}$ is less than $1 / 4$ will never happen. The linear strategy equilibrium missed all these transactions with the condition that $\mathrm{v}$ is less than c plus $1 / 4$, but allowed all the transactions if v subtracting $\mathrm{c}$ is greater than $1 / 4$.

\section{Conclusions}

This thesis analyzed the existence of the Nash equilibrium solutions when the electricity power buyer and seller adopt the linear strategies. Based on the analysis, electric power generating profits can be redistributed between the power generator and the electric power transmission provider by introducing marketization to the electric power transactions. And the power generator would have 
more incentive to generate electric power. This will help us to deal with the electric power shortage resulting from the lacking of economic incentive to generate electric power. Such an attempt will truly lead electric trading market into market-oriented but not government-oriented.

However, there are still some questions need to be resolved. In general, any transaction would promote the Pareto efficiency if the product value to the buyer is greater than the product cost to the seller. However, in the bilateral transactions, none of the Bayesian Nash equilibrium can make Pareto efficient transactions happen definitely and only. So maybe the transaction will never occur even though the value to the buyer is greater than the cost to the seller. Yet, it is Pareto efficient. So, how to ensure each transactions completed is also worthy of further research in the basis of bilateral transactions.

\section{References}

[1] Yonggan, W.: Electricity Market Introduction, China Electric Power Press, Beijing, (2002).

[2] Yang, H.Y.: Energy Economics, Vol. 22(2000), p. 309.

[3] Weiying, Z.: Game Theory and Information Economics, Shanghai People's Publishing Press, Shanghai, (2010).

[4] Soytas, U., Sari, R.: Energy Economics, Vol. 25(2003), p. 33.

[5] Chang, T.S., Fang, W., Wen, L.: Applied Economics, Vol. 33(2001), p. 1045.

[6] Kao, C. and Chiang, M.H.: Advances in Econometrics, Vol. 15(2000), p. 179.

[7] Glasure, Y.U., Angirasa, A., Lee, A.: Journal of Energy Development, Vol. 24(2000), p. 55. 